rights and property, table manners, ability to rise at correct time, sexual awareness.

Control of any psychiatric symptoms or disabilities

Anxiety, phobias, affective illness, schizophrenia, personality traits, eating disorder, drug abuse, need for specialist psychiatric out-patient follow-up.

\section{Psychiatric medication}

Prescriptions - by GP, side effects, compliance, depot injections - administration by GP, nurse; monitoring of blood levels, e.g., lithium; supplying drug information leaflets to carers.

Other therapies

Counselling, relaxation, others.

General medical conditions and treatments

Epilepsy - blood levels of anti-epileptic drugs, seizure record card; heart, chest, gastrointestinal, genito-urinary, neurological, skeletal disorders; vision, hearing; contraceptive measures.

Dental care

\section{Study leave to attend College meetings \\ DeAR SIRS}

The concern is expressed by junior psychiatrists that there are often considerable difficulties experienced in obtaining study leave to attend College meetings. Unfortunately it appears that, despite previous concern within the College and the JCHPT that attendance at national scientific meetings is a necessary part of training, some senior house officers and registrars cannot obtain the leave and/or funding.

This issue has once more been taken up by the Collegiate Trainees, Committee and, to that end, a survey of the national position was undertaken through regional representatives. The results make interesting reading with large disparities between different geographical areas and training schemes.
The majority of areas have a half-day release course in preparation for the MRCPsych examinations, using up 15 of the allotted study leave days. The availability of time and expenses to attend College meetings and other courses of personal professional interest is therefore reasonably good.

There is the increasing trend, however, for some training schemes, such as those based in Mersey, Leeds, South Manchester and Edinburgh to run their own (e.g. MSc/MPhil) courses. These require a full day commitment per week and can cost the relevant Health Authority up to $£ 1,000$ per year. Such courses of study are more or less compulsory and do not allow trainees the right to determine how their study leave allocation is spent.

Certain regions have more serious problems. One trainee in Basingstoke was not even granted travel expenses to attend the region's own course until the BMA threatened to take court action. Junior psychiatrists in Northern Ireland are severely restricted in their ability to attend meetings in England, and certain Health Boards in Eire do not pay expenses to attend local courses in preparation for the MRCPsych.

In addition, some worrying trends emerge. Study leave is increasingly becoming cash limited with severe constraints placed on juniors only to attend local courses. Pooling of study leave budgets between doctors and, in some cases, all mental health professionals, has led to total non-availability of study leave towards the end of the financial year (Oxford, York).

It is clear that the College should stress, once more, that adequate study leave with expenses, which should include the opportunity to attend College meetings, is a prerequisite for continued approval of schemes for training purposes.

C. P. Lucas

Collegiate Trainees, Committee

\title{
Correction
}

In the letter entitled 'Models of care for AIDS dementia' (Psychiatric Bulletin, June 1990, 14, 365) reference is made to Professor Beverley Raphael as "he". This is incorrect - Professor Raphael is female. 